\title{
Clinical classification of cardiovascular tumors and tumor-like lesions, and its incidences
}

\author{
Jun Amano · Jun Nakayama • Yasuo Yoshimura • \\ Uichi Ikeda
}

Received: 14 November 2012/Published online: 5 March 2013

(c) The Author(s) 2013. This article is published with open access at Springerlink.com

\begin{abstract}
Tumors of the heart and the great vessels are very rare disease, and there are many disorders such as tumors originated from the heart and great vessels, metastatic tumors, and tumor-like lesions which do not fit into the usual concept of tumor or neoplasm; thus, it is very difficult to classify these tumors. We proposed a new classification of cardiovascular tumors for clinical use based on the accumulated biological analyses and clinical data of the reported literatures and our own study as benign tumors, malignant tumors, ectopic hyperplasia/ectopic tumors/others, and tumors of great vessels, with reference to the series of Atlas of tumor pathology of the Armed Forces Institute of Pathology and the recent World Health Organization classification of cardiac tumors issued in 2004. More than 50 disorders have been reported as tumors
\end{abstract}

The review was submitted at the invitation of the editorial committee.

J. Amano $(\bowtie)$

Department of Cardiovascular Surgery,

Shinshu University School of Medicine,

3-1-1 Asahi, Matsumoto, Nagano, Japan

e-mail: junamano@shinshu-u.ac.jp

J. Nakayama

Department of Molecular Pathology,

Shinshu University Graduate School of Medicine,

3-1-1 Asahi, Matsumoto, Nagano, Japan

\section{Y. Yoshimura}

Department of Orthopaedic Surgery,

Shinshu University School of Medicine,

3-1-1 Asahi, Matsumoto, Nagano, Japan

U. Ikeda

Department of Cardiovascular Medicine,

Shinshu University School of Medicine,

3-1-1 Asahi, Matsumoto, Nagano, Japan originated from the cardiovascular system, and various metastatic tumors from nearby organs, distant lesions, and intravascular extension tumors to the heart were reported. Based on the new classification, we reviewed epidemiology and incidence of cardiovascular tumors. Metastatic tumors are more frequent than tumors originated from the heart and great vessels, and cardiac myxoma is the most frequent tumors in all cardiac tumors.

Keywords Cardiac tumor - Metastatic cardiac tumors . Classification · Incidence $\cdot$ Cardiac myxoma

\section{Introduction}

Tumors of the cardiovascular system, benign or malignant, are very rare disease, and there are many disorders which do not fit into the concept of tumor or neoplasm; thus, it is very difficult to classify the tumors of the heart and great vessels. As tumors of other organ, tumor of the heart and great vessels are classified as tumors originated from the heart and great vessels, or secondary/metastatic tumor with invasion nearby organs such as lung or metastatic tumors that occur in the distant organ. In addition, tumors originated from the heart are classified by the site of tumor location such as tumor of the heart, cardiac septum, pericardium, or great vessels, and classified by cell type constituting the tumor such as hyperplasia, hamartoma, cyst, or benign or malignant, and also classified by histological features such as mesenchymal, epithelial, and serous membrane (mesothelium). However, there is no established standard method of classification of tumors of the heart and great vessels up to now. In this review, we propose a new clinical classification for tumors of the cardiovascular 
system, and summarize its epidemiology and incidence from the reported literatures and our own study.

\section{Classification of tumors of the heart and great vessels}

Tumors originated from the heart and great vessels are found at an incidence of about $0.02 \%$ of autopsy. Among these cardiovascular tumors, $70 \%$ of these tumors and most of the surgically excised tumors are benign [1]. Since there is no counterpart tumor in other organs or lack of histogenetical and pathological evidence of true tumor for papillary fibroelastoma, histiocytoid cardiomyopathy, lipomatous hypertrophy of the interatrial septum or cystic tumor of atrioventricular node, and others, pathological classification is very difficult for these tumors [2]. And also, it seems difficult to classify the tumors by histological type, because there are many tumors whose origin is not clear like tumors appear in other organs and tissues. A typical example is that in cardiac myxoma, origin of cardiac myxoma and tumor characteristics is not yet elucidated, and it contains various cell components like epithelium, endothelium, nerve, and undifferentiated mesenchyma which potentially differentiate into many tissues such as blood vessels, glandular structures, bones, and foci of extramedullary hematopoiesis [3]. Also, sarcoma is a malignant cardiovascular tumor, and despite very low incidence, many types of sarcomas which found in other organs were reported in the literatures [4]. However, there is so-called undifferentiated sarcoma exists that cannot determine a certain tendency to differentiate into cells or tissues even if using the latest diagnostic technology such as immunohistochemistry, electron microscopy and genetic analysis [5].

Because there are many cardiac tumors whose origin is not yet determined and cell differentiation was not elucidated, it is very difficult to systematically classify these tumors. According to the well-known classification of "tumors of the heart and great vessels" (Armed Forces Institute of Pathology: AFIP) published in 1996 [3] (Table 1), cardiac tumors including both cardiac tumors and pericardial tumors are classified into benign or malignant cardiac tumors. Sarcomas of the aorta and pulmonary artery, sarcomas of the inferior vena cava, and leiomyomatosis of veins are classified in different categories. Benign cardiac tumors are further classified as tumors of unknown histogenesis, tumors of cardiac muscle, tumor of fibrous tissue, vascular tumors and tumor-like lesions, tumors and proliferations of fat, tumors and tumor-like lesions of mesothelial cells, tumors of neural tissue, tumors of smooth muscle, heterotopias, and tumors of ectopic tissue. And malignant cardiac tumors are classified as sarcomas, malignant germ cell tumors, hematologic
Table 1 Classification of "tumors of the heart and great vessels" by the Armed Forces Institute of Pathology

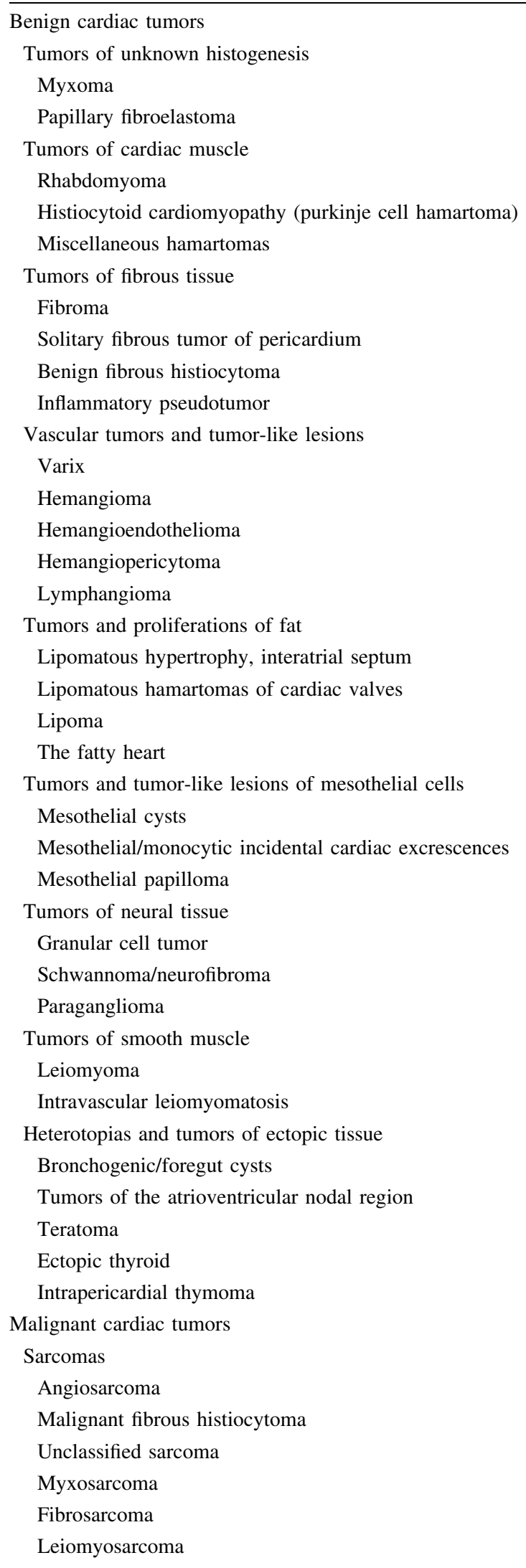


Table 1 continued

Rhabdomyosarcoma
Osteosarcoma
Synovial sarcoma
Malignant schwannoma (malignant peripheral nerve sheath
tumor)
Malignant mesenchymoma
Malignant hemangiopericytoma
Kaposi's sarcoma
Malignant germ cell tumors
Hematologic tumors
Lymphoma
Granulocytic sarcoma
Mesothelial malignancies
Malignant mesothelioma
Metastatic tumors to the heart
Sarcomas of the aorta and pulmonary artery
Luminal (intimal) sarcoma
Unclassified sarcomas
Malignant fibrous histiocytoma
Angiosarcoma
Osteosarcoma
Chondrosarcoma
Leiomyosarcoma
Malignant mesenchymoma
Mural sarcomas
Leiomyosarcoma
Angiosarcoma
Malignant fibrous histiocytoma (MFH)
Unclassified sarcomas
Muram of the inferior vena cava
Mesarcoma
Meins

Modified from reference [3]

tumors, granulocytic sarcoma, mesothelial malignancies, and metastatic tumors to the heart.

The recent classification by WHO in 2004, tumor of the heart are divided into three categories: benign tumors and tumor-like lesions, malignant tumors, and pericardial tumors [4] (Table 2). In benign tumors, tumor were classified as tumor showing differentiation into muscle cells such as rhabdomyoma, adult cellular rhabdomyoma, hamartoma of mature cardiac myocytes, and histiocytoid cardiomyopathy. Cardiac myxoma and papillary fibroelastoma are classified as pluripotent mesenchymal origin, and cardiac fibroma and inflammatory myofibroblastic tumor were classified as tumor showing differentiation into myofibroblastic cell. Other benign tumors are vascular tissue origin as hemangioma, fat tissue origin as lipoma, and
Table 2 WHO histological classification of tumors of the heart

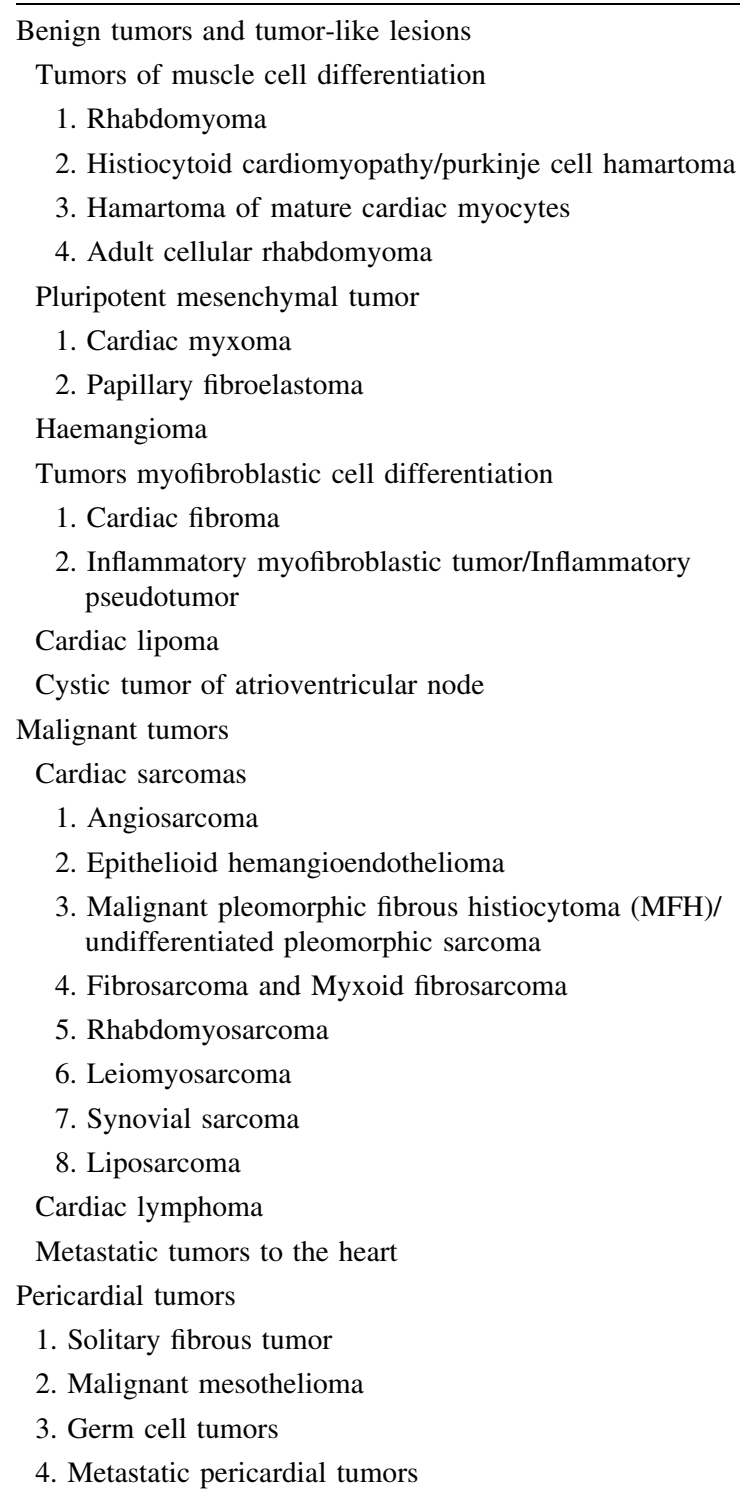

congenital cystic lesions in the atrioventricular node as cystic tumor of atrioventricular node. This classification includes relatively high incidence of benign cardiac tumors, however, tumors of low incidence such as tumors of neural cell differentiation or smooth muscle cell differentiation are not included. Most prominent differences of WHO classification from AFIP classification are classification of malignant tumors. Firstly, epithelioid hemangioendothelioma, formerly classified as benign tumor has been classified as malignant tumor, and secondarily undifferentiated sarcoma, which has been classified as tumor of unknown origin, is united to form one disease as malignant pleomorphic fibrous histiocytoma (MFH)/ undifferentiated pleomorphic sarcoma subtype. Other 
features of WHO classification are malignant mesenchymoma, osteosarcoma, chondrosarcoma, and many other sarcomas were not included as an independent sarcoma, but included in MFH/undifferentiated pleomorphic sarcoma, and tumor that had been referred to as myxosarcoma specific for heart was classified as a subtype of myxoid fibrosarcoma.

Since the AFIP classification of the heart, pericardium, and great vessels has been widely used, we propose a new classification based on AFIP classification, with reference to the WHO classification and taking into account the recent findings of cell differentiations and clinical importance [6] (Table 3). Cardiac tumors are classified as benign tumors, malignant tumors, and ectopic cardiac tumors and other tumors. Benign tumors are classified into cardiac

Table 3 Classification of tumors of the heart and great vessels: new classification based on the cell differentiation and clinical importance

Benign tumors

I. Cardiac tumors

Cardio-specific tumors

1. Cardiac myxoma

2. Papillary fibroelastoma

Tumors and tumor-like lesions of muscle cell differentiation

3. Rhabdomyoma

4. Leiomyoma

5. Histiocytoid cardiomyopathy/purkinje cell hamartoma

Tumors of fibroblast and myofibroblast cell differentiation

6. Cardiac fibroma

7. Inflammatory myofibroblastic tumor/inflammatory pseudotumor

Tumors of vascular vessel and lymphatic vessel differentiation

8. Hemangioma

9. Angiomyolipoma

10. Hemangiopericytoma

11. Lymphangioma

Tumors and tumor-like lesions of adipocyte differentiation

12. Lipomatous hypertrophy

13. Lipoma

14. Lipomatous hamartoma of cardiac valves

Tumors of nerve cell and nerve sheath differentiation

15. Granular cell tumor

16. Paraganglioma

17. Neurofibroma

18. Neurinoma/Schwannoma

Other cardiac tumors and tumor-like lesions

19. Teratoma

20. Hamartoma

21. Cystic tumor of atrioventricular node

II. Pericardial tumors and tumor-like pericardial lesions

22. Solitary fibrous tumor of the pericardium
Table 3 continued

23. Mesothelial papilloma

24. Intrapericardial thymoma/pericardial thymoma

25. Pericardial cyst

Malignant tumors

I. Cardiac tumors originated from the heart

1. Angiosarcoma

2. Cardiac intimal sarcoma

3. Epithelioid hemangioendothelioma

4. Malignant pleomorphic fibrous histiocytoma (MFH)/ undifferentiated pleomorphic sarcoma

5. Osteosarcoma

6. Rhabdomyosarcoma

7. Leiomyosarcoma

8. Fibrosarcoma/myxosarcoma

9. Synovial sarcoma

10. Liposarcoma

11. Malignant schwannoma

12. Malignant lymphoma

II. Metastatic cardiac tumors

1. Direct invasion

2. Metastasis

III. Intravascular extension tumors

1. Renal cell carcinoma

2. Leiomyomatosis of veins

IV. Pericardial tumors

1. Malignant mesothelioma

2. Metastatic tumors

3. Leukemic infiltration of the pericardium

Ectopic hyperplasia/Ectopic tumors · Others

1. Aberrant goiter/Thyroid heterotopia/ectopic thyroid

2. Bronchogenic cyst

3. Mesothelial/Monocyte incidental cardiac excrescence (MICE)

4. Blood cyst

5. IgG4-related sclerosing disease

6. Immunodeficiency-associated lymphoproliferative disorder

7. Wegener's granulomatosis

8. Calcified amorphous tumor

9. Thrombus

Tumors of the great vessels

1. Aortic tumors

2. Pulmonary artery tumors

3. Tumors of the great veins

Modified from reference [6]

tumors and pericardial tumors. Malignant tumors are classified as tumors originated from the heart, metastatic cardiac tumors, intravascular tumors with extension to the heart, and malignant pericardial tumors. The tumors of ectopic cardiac tumors and other tumors are tumors of unknown origin, ectopic other tissue formation within the 
heart, tumor-like lesions due to immunological or hematological disorders, and apparently no tumor lesion but should be differential diagnosed. IgG4-related sclerosing disease are included in this classification as a cardiac tumor, since this disorder are reported to be systemic immunological disorder and forming lesions in the salivary glands as well as pancreas and tumor-like lesion in the heart. In addition, the immunodeficiency-associated lymphoproliferative disorder due to the recent spread of AIDS has been included in this category. Thrombus is not a true tumor, and it was not included in the AFIP classification. We picked up thrombus as "other disease", because it is useful for routine clinical differential diagnosis when intracavitary or intravascular lesions is encountered.

Tumors of the great vessels are further rare tumors compared to the cardiac tumors. Most of them have been malignancies in the aorta, pulmonary artery, and vena cava, and the high incidence in the venous system. The classification of the tumors of great vessels is not well established because of its very low incidence and lack of pathological analyses [7]. For malignant tumor that occurs in the aorta, Iwabuchi [8] classified aortic tumors following two types, i.e., intimal or luminal type which main lesion is in the intima, and the mural type which main lesion is in the media to adventitia, since histological classification did not reflect patient prognosis, but tumor locations and shape is clinically important. In particular, the intimal type of tumor when tumor is protruding and exposed to the vessel lumen resulting strong degeneration and necrosis, is diagnosed as intimal sarcoma, because it may be difficult to diagnose pathology correctly due to poor pathological specimen.

Our new classification of tumors of the heart and great vessels are based on the "tumors of the heart and great vessels" AFIP [1] and the WHO classification [4]. The pathological and clinical entities of these tumors were not well established compared with other organs such as tumors of the digestive system, and the WHO classification classified only typical tumor and major cardiac tumors and tumor-like lesions. In our classification, we intended to include almost all the tumors and tumor-like lesions of the heart and great vessels for clinical use based on the idea of the authors. Since this classification is not perfect and did not based on fully pathological aspects, we sincerely hope that the more precise and useful classifications will be established in accordance with the development of studies about tumors of the heart and great vessels.

\section{Epidemiology and incidence}

The cardiovascular tumor is rarely encountered, and its incidence is very low among tumors of all organs. In the
Table 4 Incidence of primary cardiac tumors diagnosed at autopsy

\begin{tabular}{lrrl}
\hline Authors & $\begin{array}{l}\text { Autopsy } \\
\text { cases }\end{array}$ & $\begin{array}{l}\text { Primary cardiac } \\
\text { tumors }\end{array}$ & $\begin{array}{l}\text { Incidence } \\
(\%)\end{array}$ \\
\hline Pollia & 46,072 & 154 & 0.33 \\
Benjamin & 40,000 & 12 & 0.003 \\
Straus & 480,000 & 8 & 0.0017 \\
Reynen & 731,309 & 15,357 & 0.021 \\
Mayo clinic & & & \\
$\quad$ Lymburner: $1915-1931$ & 8,550 & 4 & 0.047 \\
$\quad$ Wold: $1954-1979$ & 23,673 & 41 & 0.17 \\
Mukai & 2,649 & 1 & 0.038 \\
Nadas & & & 0.01 \\
\hline
\end{tabular}

Modified from reference [10]

past, cardiac tumors are very difficult to diagnose before life and it was often discovered incidentally at autopsy. However, recent advances in diagnostic techniques such as echocardiography and computed tomography (CT) enabled clinical diagnosis during lifetime, and pathological diagnosis of tumor can be obtained by surgically removed tumors or biopsy. From these accumulated pathological and clinical data, it became evident that many varieties of tumors occur in the heart and great vessels as in other organs.

The incidence of cardiac tumors in autopsy

The incidence of cardiac tumors in autopsy cases has been reported from long time ago, it has been observed difference almost 100 times by the reporter from 0.33 to $0.0017 \%$ so far as in the literatures (Table 4). This wide range of incidence may be due to changes of criteria for pathological diagnosis, transition of subjects for autopsy, and changes of diseases for autopsy [9, 10]. Pollia and Gogol [11] reported the highest incidence of tumors originated from the heart as $0.33 \%$ (154 cases) in autopsy of 46,072 cases, while Straus and Merliss [12] reported the lowest incidence as $0.0017 \%$ (8 cases) in autopsy of 480,000 cases by summarizing the autopsy statistics of six hospitals. Reynen [13] reported the incidence as $0.021 \%$ in 731,309 autopsy cases by summarizing the autopsy statistics from the 22 literatures. It is interesting the presence of year difference of incidence of tumors originated from the heart that incidence of the years 1915-1931 is $0.047 \%$, while $0.17 \%$ in the years $1954-1979$ from the report of Mayo Clinic [10, 14]. In Japan, Mukai et al. [15] from National Cancer Center reported that tumors originated from the heart was found only in 1 case $(0.038 \%)$ during the year 1976-1985 among 2,649 autopsy cases who died of cancer. On the other hand, reports of cardiac tumors in children are scarce, Nadas and Ellison [16] 
Table 5 Incidence of tumors originated from the heart

\begin{tabular}{|c|c|c|c|}
\hline Tumors & AFIP-1975 & AFIP 1976-1993 & Surgical cases \\
\hline \multicolumn{4}{|l|}{ Benign } \\
\hline Myxoma & $130(24.4 \%)$ & $114(29.5 \%)$ & $102(36.7 \%)$ \\
\hline Papillary fibroelastoma & $42(7.9 \%)$ & $31(8.0 \%)$ & $8(2.9 \%)$ \\
\hline Rhabdomyoma & $36(6.8 \%)$ & $20(5.2 \%)$ & $6(2.2 \%)$ \\
\hline Fibroma & $17(3.2 \%)$ & $20(5.2 \%)$ & $18(6.5 \%)$ \\
\hline Hemangioma & $15(2.8 \%)$ & $17(4.4 \%)$ & $10(3.6 \%)$ \\
\hline Lipomatous hypertrophy & 0 & $12(3.1 \%)$ & $7(2.5 \%)$ \\
\hline Cystic tumor of AV node & $12(2.3 \%)$ & $10(2.6 \%)$ & 0 \\
\hline Granular cell tumor & $3(0.56 \%)$ & $4(1.0 \%)$ & 0 \\
\hline Lipoma & $45(8.4 \%)$ & $2(0.5 \%)$ & $2(0.07 \%)$ \\
\hline Paraganglioma & 0 & $2(0.5 \%)$ & $2(0.07 \%)$ \\
\hline Hamartoma & 0 & $2(0.5 \%)$ & $2(0.07 \%)$ \\
\hline Histiocytoid cardiomyopathy & 0 & $2(0.5 \%)$ & 0 \\
\hline Inflammatory pseudotumor & 0 & $2(0.5 \%)$ & $2(0.07 \%)$ \\
\hline Fibrous histiocytoma & 0 & $1(0.25 \%)$ & 0 \\
\hline Epithelioid hemangioendothelioma & 0 & $1(0.25 \%)$ & $1(0.04 \%)$ \\
\hline Pericardial cyst & $82(15.4 \%)$ & 0 & 0 \\
\hline Bronchogenic cyst & $7(1.3 \%)$ & $1(0.25 \%)$ & $1(0.04 \%)$ \\
\hline Teratoma & $14(2.6 \%)$ & $1(0.25 \%)$ & 0 \\
\hline Others & $5(0.94 \%)$ & 0 & 0 \\
\hline Total & $408(76.5 \%)$ & $242(62.7 \%)$ & $161(57.9 \%)$ \\
\hline \multicolumn{4}{|l|}{ Malignant } \\
\hline Angiosarcoma & $39(7.3 \%)$ & $33(8.5 \%)$ & $22(7.9 \%)$ \\
\hline Undifferentiated sarcoma & 0 & $33(8.5 \%)$ & $30(10.8 \%)$ \\
\hline Malignant fibrous histiocytoma & 0 & $16(4.1 \%)$ & $16(5.8 \%)$ \\
\hline Osteosarcoma & $5(0.94 \%)$ & $13(3.4 \%)$ & $13(4.7 \%)$ \\
\hline Leiomyosarcoma & $1(0.19 \%)$ & $12(3.1 \%)$ & $11(4.0 \%)$ \\
\hline Fibrosarcoma & $14(2.6 \%)$ & $9(2.3 \%)$ & $9(3.2 \%)$ \\
\hline Myxosarcoma & 0 & $8(2.1 \%)$ & $8(2.9 \%)$ \\
\hline Rhabdomyosarcoma & $26(4.9 \%)$ & $6(1.6 \%)$ & $2(0.07 \%)$ \\
\hline Synovial sarcoma & $1(0.19 \%)$ & $4(1.0 \%)$ & $4(1.4 \%)$ \\
\hline Liposarcoma & $1(0.19 \%)$ & $2(0.5 \%)$ & 0 \\
\hline Malignant schwannoma & $4(0.75 \%)$ & $1(0.25 \%)$ & $1(0.04 \%)$ \\
\hline Malignant mesothelioma & $19(3.6 \%)$ & 0 & 0 \\
\hline Others & $8(3.6 \%)$ & 0 & 0 \\
\hline Total & $118(23.5 \%)$ & $137(35.5 \%)$ & $116(41.7 \%)$ \\
\hline Malignant lymphoma & $7(1.3 \%)$ & $7(1.8 \%)$ & $1(0.04 \%)$ \\
\hline Total & 533 & 386 & 278 \\
\hline
\end{tabular}

reported that incidence of tumors originated from the heart was $0.01 \%$ at autopsy.

Tumors originated from the heart

The incidence of tumors originated from the heart has changed over the years and the development of medicine between the recent era when the diagnostic methods and surgical resection developed and the era when most of the cardiac tumors were diagnosed by autopsy.
In the AFIP data $[3,17]$, cardiac myxoma is the most common cardiac tumor accounting for 24-37\% of them, following angiosarcoma (7.3-8.5\%), and papillary fibroelastoma is observed (from 7.9-8.0 \%) with approximately the same frequency. Benign tumors are more common in order of myxoma, papillary fibroelastoma, rhabdomyoma, fibroma, hemangioma, and cystic tumor of atrioventricular node, and malignant tumors are more common in order of angiosarcoma, unclassified sarcoma, and malignant fibrous histiocytoma (Table 5). In comparison with adults, the 
Table 6 Incidence of tumors originated from the heart in infancy (under 16 years)

\begin{tabular}{|c|c|c|c|c|}
\hline \multirow{2}{*}{$\begin{array}{l}\text { Table } 6 \text { Incidence of tumors } \\
\text { originated from the heart in } \\
\text { infancy (under } 16 \text { years) }\end{array}$} & Tumors & \multirow[t]{2}{*}{$\begin{array}{l}\text { AFIP } \\
<1 \text { year }\end{array}$} & \multirow[t]{2}{*}{$<16$ years } & \multirow[t]{2}{*}{$\begin{array}{l}\text { Becker } \\
<16 \text { years }\end{array}$} \\
\hline & Benign & & & \\
\hline & Myxoma & 0 & $4(7.1 \%)$ & 0 \\
\hline & Rhabdomyoma & $19(54.3 \%)$ & $20(35.7 \%)$ & $9(42.9 \%)$ \\
\hline & Fibroma & $8(22.9 \%)$ & $13(23.2 \%)$ & $5(23.8 \%)$ \\
\hline & Histiocytoid cardiomyopathy & $2(5.7 \%)$ & $2(3.6 \%)$ & $2(9.5 \%)$ \\
\hline & Hemangioma & $1(2.9 \%)$ & $2(3.6 \%)$ & $2(9.5 \%)$ \\
\hline & Cystic tumor of AV node & $1(2.9 \%)$ & $2(3.6 \%)$ & 0 \\
\hline & Inflammatory pseudotumor & 0 & $1(1.8 \%)$ & 0 \\
\hline & Teratoma & $1(2.9 \%)$ & $1(1.8 \%)$ & 0 \\
\hline & Lipoma & 0 & 0 & $1(4.8 \%)$ \\
\hline & Total & $32(91.3 \%)$ & $45(80.4 \%)$ & $19(90.5 \%)$ \\
\hline & Malignant & & & \\
\hline & Rhabdomyosarcoma & $1(2.9 \%)$ & $3(5.4 \%)$ & 0 \\
\hline & Angiosarcoma & 0 & $1(1.8 \%)$ & 0 \\
\hline & Undifferentiated sarcoma & $1(2.9 \%)$ & $3(5.4 \%)$ & $1(4.8 \%)$ \\
\hline & Malignant fibrous histiocytoma & $1(1.8 \%)$ & 0 & \\
\hline & Leiomyosarcoma & $1(2.9 \%)$ & $1(1.8 \%)$ & $1(4.8 \%)$ \\
\hline & Fibrosarcoma & 0 & $1(1.8 \%)$ & 0 \\
\hline Modified from references $[3$, & Myxosarcoma & 0 & $1(1.8 \%)$ & 0 \\
\hline 18] & Total & $3(8.7 \%)$ & $11(19.6 \%)$ & $2(9.5 \%)$ \\
\hline AFIP Armed Forces Institute of & Total & 35 & 56 & 21 \\
\hline
\end{tabular}

Modified from references [3,

18]

AFIP Armed Forces Institute of Pathology
Table 7 Susceptible age when cardiac tumors have been diagnosed

\begin{tabular}{|c|c|c|c|}
\hline Tumors & AFIP & $\begin{array}{l}\text { Endo } \\
\text { (years) }\end{array}$ & $\begin{array}{l}\text { Amano } \\
\text { (years) }\end{array}$ \\
\hline Teratoma & 16 weeks & & \\
\hline Rhabdomyoma & 33 weeks & & \\
\hline Fibroma & 13 years & & \\
\hline Rhabdomyosarcoma & 15 years & & 50.5 \\
\hline Hemangioma & 31 years & & \\
\hline $\begin{array}{l}\text { Cystic tumor of } \\
\text { atrioventricular node }\end{array}$ & 33 years & & \\
\hline All sarcomas & 41 years & & 67.2 \\
\hline Myxoma & 50 years & 58.5 & 64.0 \\
\hline Mesothelioma & 57 years & & \\
\hline Angiosarcoma & & & 57.4 \\
\hline Papillary fibroelastoma & 59 years & & 70.9 \\
\hline Lipomatous hypertrophy & 64 years & & \\
\hline Leiomyosarcoma & & & 69.8 \\
\hline
\end{tabular}

Modified from reference [9]

AFIP Armed Forces Institute of Pathology

incidence of cardiac tumors in children is very low $[3,16]$. In addition, percentages of rhabdomyoma and fibroma are especially high, and histiocytoid cardiomyopathy also is relatively high, but cardiac myxoma which is the most common in adults is characterized as less common $[3,18]$ (Table 6). Interestingly, rhabdomyoma is considered a
Table 8 Reported incidences in the regional meeting of JATS and JCS (1999-2010)

\begin{tabular}{lll}
\hline Tumors & JCS & JATS \\
\hline Benign & & \\
Myxoma & $125(34.0 \%)$ & $100(43.1 \%)$ \\
Papillary fibroelastoma & $42(11.4 \%)$ & $41(17.7 \%)$ \\
Lipoma & $9(2.4 \%)$ & $8(3.4 \%)$ \\
Hemangioma & $9(2.4 \%)$ & $6(2.6 \%)$ \\
Fibroma & $5(1.4 \%)$ & $5(2.2 \%)$ \\
Lipomatous hypertrophy & $3(0.8 \%)$ & $2(0.9 \%)$ \\
Rhabdomyoma & $1(0.3 \%)$ & 0 \\
Paraganglioma & $1(0.3 \%)$ & $2(0.9 \%)$ \\
Neurinoma & $1(0.3 \%)$ & $1(0.45 \%)$ \\
Hamartoma & $1(0.3 \%)$ & 0 \\
Lipomatous hamartoma of cardiac & $1(0.3 \%)$ & 0 \\
values & & \\
Inflammatory pseudotumor & 0 & $1(0.45 \%)$ \\
Angiomyolipoma & 0 & $1(0.45 \%)$ \\
Total & $198(53.8 \%)$ & $167(72.0 \%)$ \\
Malignant & & \\
Angiosarcoma & $30(8.2 \%)$ & $22(9.5 \%)$ \\
Malignant fibrous histiocytoma & $12(3.3 \%)$ & $10(4.3 \%)$ \\
Leiomyosarcoma & $7(1.9 \%)$ & $5(2.2 \%)$ \\
Liposarcoma & $4(1.1 \%)$ & $2(0.9 \%)$ \\
Osteosarcoma & $3(0.8 \%)$ & $3(1.3 \%)$ \\
\hline
\end{tabular}


Table 8 continued

\begin{tabular}{lll}
\hline Tumors & JCS & JATS \\
\hline Synovial sarcoma & $3(0.8 \%)$ & $2(0.9 \%)$ \\
Rhabdomyosarcoma & $3(0.8 \%)$ & $1(0.45 \%)$ \\
Fibrosarcoma & $2(0.3 \%)$ & 0 \\
Chondrosarcoma & 0 & $1(0.45 \%)$ \\
Malignant schwannoma & 0 & $1(0.45 \%)$ \\
Endothelial sarcoma & 0 & $2(0.9 \%)$ \\
Epithelioid hemangioendothelioma & 0 & $1(0.45 \%)$ \\
Others & $31(8.4 \%)$ & $1(0.45 \%)$ \\
Total & $95(25.8 \%)$ & $51(22.0 \%)$ \\
Malignant lymphoma & $75(20.4 \%)$ & $14(6.0 \%)$ \\
Total & 368 & 232 \\
\hline
\end{tabular}

Modified from reference [9]

JCS Japanese Circulation Society, JATS Japanese Association for Thoracic Surgery

specific tumor which in some cases disappears in the course of observation [16]. In children, malignant tumors originated from the heart are very rare, and leiomyosarcoma, unclassified sarcoma, and rhabdomyosarcoma are reported [3, 16].

In this way, the susceptible age when cardiac tumors have been diagnosed is different for each tumor. According to the AFIP data [3], rhabdomyoma and teratoma occur in infancy, rhabdomyosarcoma and cardiac fibroma is common in the adolescence, mesothelioma, lipomatous hyperplasia, and papillary fibroelastoma tended to occur in the elderly [3, 9, 19] (Table 7). Our results of research about cardiac tumors in Japan supported by the Grant-inaid for Scientific Research from Japan Society for the Promotion of Science (JSPS: 21591793) is not similar to that of the data of AFIP for susceptible age when cardiac tumors were diagnosed. This may be due to the small number of cases in our study compared to AFIP data and recent high incidences of presentation of cardiac tumors in the elderly in recent aging society.

Cardiac tumors have been reported frequently in the regional meetings of the Japanese Association for Thoracic Surgery (JATS) and the Japanese Circulation Society (JCS). Compiling the tumor incidence by reported cases that have been reported in the meeting of regional meeting of JATS and JCS during the years 1999-2010, the most frequent benign tumor was cardiac myxoma (34.0-43.1\%), followed by papillary fibroelastoma (11.4-17.7\%), lipoma (2.4-3.4\%), and hemangioma (2.4-2.6\%) in the order [9] (Table 8). On the other hand, frequency of the malignant cardiac tumor with the exception of malignant lymphoma was angiosarcoma (8.2-9.5\%), malignant fibrous histiocytoma (3.3-4.3\%), and leiomyosarcoma (1.9-2.2\%) in the order. Although the approximate frequency rate of cardiac tumors were similar among regional meeting of JATS and JCS, it may be possible that the same case have been reported in both meetings. However, for malignant lymphoma, different incidence between JCS: $20.4 \%$ and JATS: $6.0 \%$ may reflect that radiation therapy and

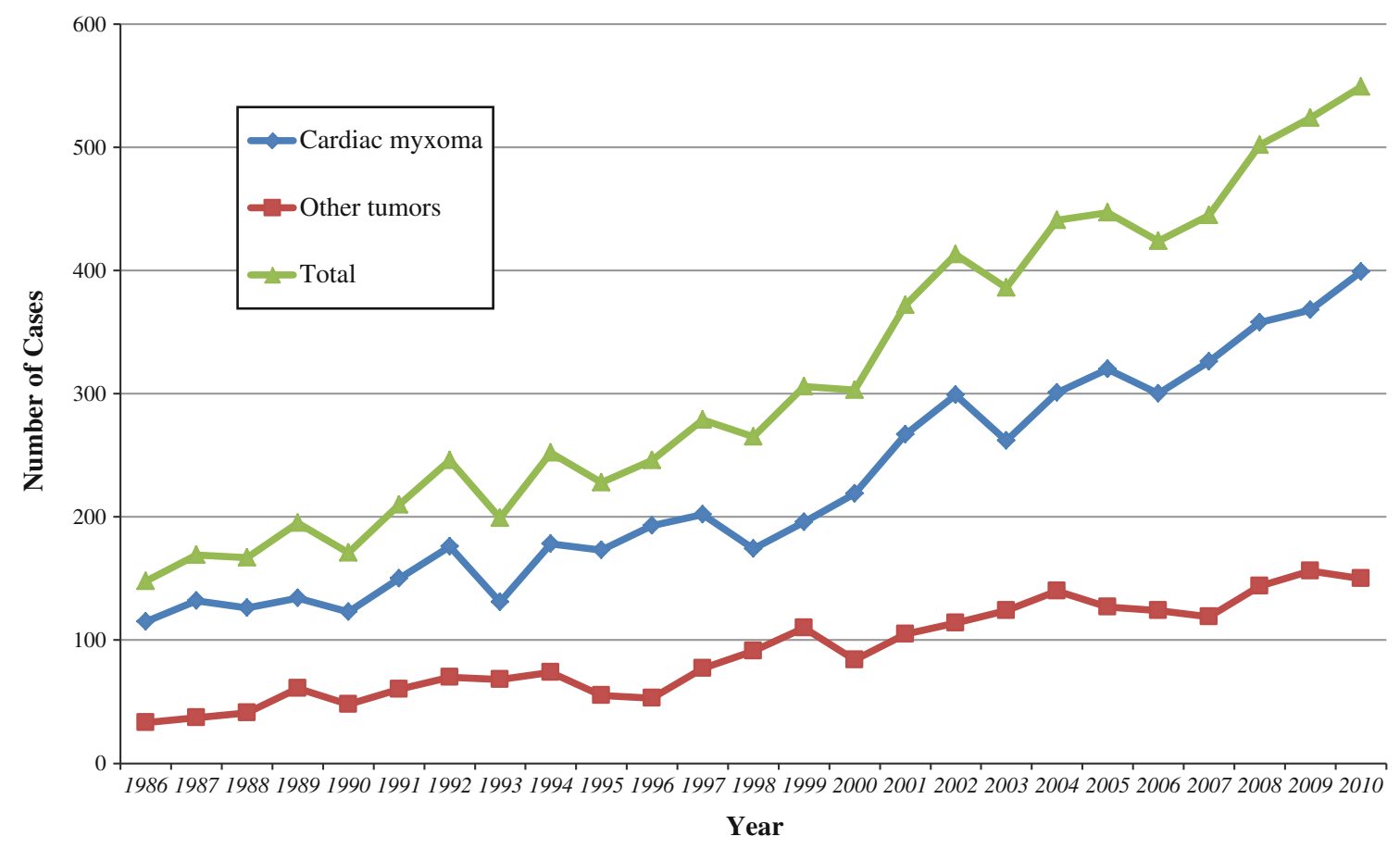

Fig. 1 Changes of cases of reported cardiac tumors by the annual report by The Japanese Association for Thoracic Surgery 
Table 9 Incidence of tumors originated from the heart and the pericardium in Japan (2009)

\begin{tabular}{lc}
\hline Tumors & Cases \\
\hline Benign & \\
Myxoma & $332(69.9 \%)$ \\
Papillary fibroelastoma & $46(9.7 \%)$ \\
Rhabdomyoma & $5(1.1 \%)$ \\
Lipomatous hypertrophy & $1(0.2 \%)$ \\
Lipoma & $1(0.2 \%)$ \\
Granular cell tumor & $1(0.2 \%)$ \\
Paraganglioma & $1(0.2 \%)$ \\
Neurinoma & $1(0.2 \%)$ \\
Hamartoma & $1(0.2 \%)$ \\
PEComa & $1(0.2 \%)$ \\
Total & $390(82.1 \%)$ \\
Malignant & \\
Angiosarcoma & \\
Malignant fibrous histiocytoma & $14(3.0 \%)$ \\
Rhabdomyosarcoma & $5(1.1 \%)$ \\
Leiomyosarcoma & $4(0.8 \%)$ \\
Osteosarcoma & $4(0.8 \%)$ \\
Synovial sarcoma & $2(0.4 \%)$ \\
Total & $1(0.2 \%)$ \\
Malignant lymphoma & $30(6.3 \%)$ \\
Unknown & $43(9.1 \%)$ \\
Pericardial tumor & $10(2.1 \%)$ \\
Malignant mesothelioma & \\
Total & $2(0.4 \%)$ \\
\hline Modied & 475 \\
\hline
\end{tabular}

Modified from reference [9]

PEComa perivascular epithelioid cell tumor chemotherapy is the subject of treatment and surgery have been attempted to patients only for open biopsy due to failure of non-invasive tissue diagnosis or for life-saving surgery for patients suffering from heart failure due to intracavitary obstructing tumor. In addition, since the relatively rare cases tend to be reported at such regional meetings, it is plausible that these data did not reflect the actual incidence of tumor in Japan.

Regarding number of cases of surgery for cardiac tumors in Japan, there are annual statistics of JATS; since the survey began in 1986, incidence of cardiac tumor has been increasing every year. Recently, about 400-500 cases have been operated in every year, and cardiac myxoma accounts for about $70 \%$ of them (Fig. 1).

By our research project for cardiac tumors in Japan supported by the Grant-in-aid for scientific research from Japan Society for the Promotion of Science, we send out questionnaires to the JATS- and JCS-certified 1,789 hospitals in 2010 asking the cardiac tumor incidence between January and December, 2009. As a result, 580 cases with cardiovascular tumors have been experienced in 326 hospitals, most of 389 cases $(67.1 \%)$ were benign tumors originated from the heart, following malignant tumors originated from the heart were 90 cases $(15.5 \%)$ and metastatic tumors were 75 cases (12.9\%) [9] (Table 9). In addition, 12 cases of pericardial tumor $(2.1 \%)$, and 14 cases of tumor of the great vessels $(2.4 \%)$ have been experienced. Considering the annual statistics from JATS and this clinical epidemiological study in Japan, it is
Table 10 Reported incidences of metastatic cardiac tumors

\begin{tabular}{|c|c|c|c|c|c|c|c|}
\hline \multirow{2}{*}{$\begin{array}{l}\text { Table } 10 \text { Reported incidences } \\
\text { of metastatic cardiac tumors }\end{array}$} & \multirow[t]{2}{*}{ Authors } & \multirow[t]{2}{*}{ Years } & \multirow[t]{2}{*}{ Autopsy cases } & \multirow[t]{2}{*}{ Cancer cases } & \multirow[t]{2}{*}{ Cardiac metastasis } & \multicolumn{2}{|l|}{ Incidence (\%) } \\
\hline & & & & & & In cancer cases & In autopsy cases \\
\hline & $1917-1951$ & & & & & & \\
\hline & Symmers & 1917 & 298 & & 5 & 1.7 & \\
\hline & Willis & 1933 & 323 & & 20 & 6.2 & \\
\hline & Burke & 1934 & 327 & & 14 & 4.3 & \\
\hline & Pollia & 1936 & 1,450 & & 29 & 2.0 & \\
\hline & Scott & 1939 & 1,082 & & 101 & 9.3 & \\
\hline & Ritchie & 1941 & 857 & & 16 & 1.9 & \\
\hline & Prichard & 1951 & 4,375 & & 146 & 3.3 & \\
\hline & Total & & 8,712 & & 331 & 3.8 & \\
\hline & $1975-2007$ & & & & & & \\
\hline & Abioye & 1975 & 6,064 & 752 & 64 & 8.5 & 1.1 \\
\hline & Ambrosio & 1980 & 2,222 & 590 & 38 & 6.4 & 1.7 \\
\hline & Xiong & 1986 & 2,050 & 484 & 68 & 14.0 & 3.3 \\
\hline & Karwinski & 1989 & 8,571 & 2,833 & 130 & 4.6 & 1.5 \\
\hline & MacGee & 1991 & 2,455 & 1,311 & 57 & 4.4 & 2.4 \\
\hline & Silvestri & 1997 & 4,769 & 1,928 & 162 & 8.4 & 3.4 \\
\hline & Abraham & 1999 & 3,314 & 806 & 95 & 11.8 & 2.9 \\
\hline & Rafajlovski & 2005 & 11,403 & 2,928 & 79 & 2.7 & 0.7 \\
\hline & Bussani & 2007 & 18,751 & 7,289 & 662 & 9.1 & 3.5 \\
\hline & Total & & 59,599 & 18,921 & 1,355 & 7.1 & 2.3 \\
\hline
\end{tabular}


estimated that the tumors originated from the heart occurs near 500 cases per year. In this study, tumors originated from the heart have been reported 489 cases. Among these cases, the 390 cases $(79.8 \%)$ of benign cardiac tumors were more than malignancy, and 332 cases $(67.8 \%)$ were cardiac myxoma, followed by 46 cases of papillary fibroelastoma $(9.4 \%), 5$ cases of rhabdomyoma $(1.0 \%)$, lipomatous hyperplasia, lipoma, granular cell tumor, paraganglioma, schwannoma, hamartoma, and perivascular epithelioid cell

Table 11 Metastatic cardiac and pericardial tumors

\begin{tabular}{|c|c|c|c|c|}
\hline Primary lesions & Heart & $\begin{array}{l}\text { Mukai } \\
\text { pericardium }\end{array}$ & Total $(\%)$ & $\begin{array}{l}\text { Butany } \\
(\%)\end{array}$ \\
\hline Lung & 104 & 32 & $136(33.4)$ & $89(33.7)$ \\
\hline Breast & 27 & 8 & $35(8.6)$ & $31(11.7)$ \\
\hline Stomach & 22 & 8 & $30(7.4)$ & $3(1.1)$ \\
\hline Malignant lymphoma & 25 & 2 & $27(6.6)$ & $24(9.1)$ \\
\hline Esophagus & 18 & 7 & $25(6.1)$ & $8(3.0)$ \\
\hline Leukemia/Myeloma & 20 & 2 & $22(5.4)$ & $32(12.1)$ \\
\hline Uterus & 18 & 2 & $20(4.9)$ & \\
\hline Malignant melanoma & 19 & & $19(4.7)$ & $8(3.0)$ \\
\hline Sarcoma & 14 & 3 & $17(4.2)$ & \\
\hline Rectum & 9 & 3 & $12(2.9)$ & $9(3.4)$ \\
\hline Tongue & 9 & 2 & $11(2.7)$ & \\
\hline Germ cell tumor & 8 & 1 & $9(2.2)$ & \\
\hline Thyroid & 6 & & $6(1.5)$ & $1(0.4)$ \\
\hline Kidney & 4 & 1 & $5(1.2)$ & $3(1.1)$ \\
\hline Oral cavity & 4 & & $4(1.0)$ & $3(1.1)$ \\
\hline Salivary gland & 3 & 1 & $4(1.0)$ & \\
\hline Larynx & 1 & 2 & $3(1.0)$ & $1(0.4)$ \\
\hline Pharynx & 1 & 2 & $3(1.0)$ & \\
\hline Thymus & 3 & & $3(1.0)$ & \\
\hline Skin & 2 & & $2(0.5)$ & \\
\hline Bile duct & 2 & & $2(0.5)$ & \\
\hline Pancreas & 2 & & $2(0.5)$ & $10(3.8)$ \\
\hline Urinary bladder & 2 & & $2(0.5)$ & \\
\hline Unknown & 2 & & $2(0.5)$ & $16(6.1)$ \\
\hline Neuroblastoma & 1 & & $1(0.5)$ & \\
\hline Nasal/paranasal sinus & 1 & & $1(0.25)$ & \\
\hline Small intestine & & & & $1(0.4)$ \\
\hline Liver & 1 & & $1(0.25)$ & $2(0.8)$ \\
\hline Prostate & 1 & & $1(0.25)$ & \\
\hline Ovarium & 1 & & $1(0.25)$ & \\
\hline External genitalia & 1 & & $1(0.25)$ & \\
\hline Malignant melanoma & & & & $5(1.9)$ \\
\hline Reproductive organ & & & & $6(2.3)$ \\
\hline Soft tissue & & & & $8(3.0)$ \\
\hline Mediastinum & & & & $2(0.8)$ \\
\hline Brain & & & & $2(0.8)$ \\
\hline Total & 324 & 83 & 407 & 264 \\
\hline
\end{tabular}

Modified from reference [9] tumor. Eighty-eight cases (18.0\%) were malignant tumors originated from the heart, among them 43 cases $(8.9 \%)$ were malignant lymphoma, followed 9 cases $(3.5 \%)$ of

Table 12 Incidence of metastasis to the heart and the pericardium in Japan (2009)

\begin{tabular}{|c|c|}
\hline Tumors & Cases \\
\hline \multicolumn{2}{|l|}{ Heart } \\
\hline Direct invasion & $32(27.6 \%)$ \\
\hline Mediastinal tumors & $11(9.5 \%)$ \\
\hline Thymic cancer & $8(6.9 \%)$ \\
\hline Germ cell tumor & 1 \\
\hline Malignant lymphoma & 1 \\
\hline Unknown & 1 \\
\hline Lung cancer & $19(16.4 \%)$ \\
\hline Esophageal cancer & $2(1.7 \%)$ \\
\hline Distant metastasis & $39(34.5 \%)$ \\
\hline Thyroid cancer & $5(4.3 \%)$ \\
\hline Breast cancer & $3(2.6 \%)$ \\
\hline Lung cancer & $4(3.4 \%)$ \\
\hline Gastrointestinal cancer & $12(10.3 \%)$ \\
\hline Esophageal cancer & $2(1.7 \%)$ \\
\hline Gastric cancer & $3(2.6 \%)$ \\
\hline Colon cancer & 1 \\
\hline Hepatoma & $3(2.6 \%)$ \\
\hline Unknown & $3(2.6 \%)$ \\
\hline Kidney cancer & $4(3.4 \%)$ \\
\hline Seminoma & 1 \\
\hline Germ cell tumor & 1 \\
\hline Urinary bladder cancer & 1 \\
\hline Uterus cancer & 1 \\
\hline Osteosarcoma & 1 \\
\hline Soft tissue tumor & 1 \\
\hline Unknown & $5(4.3 \%)$ \\
\hline Intravascular extension & $33(28.4 \%)$ \\
\hline Renal cancer & $24(20.7 \%)$ \\
\hline Uterine tumor & $3(2.6 \%)$ \\
\hline Colon cancer & $3(2.6 \%)$ \\
\hline Hepatoma & $2(1.7 \%)$ \\
\hline Thyroid cancer & 1 \\
\hline Ureteral cancer & 1 \\
\hline Pericardium & $12(10.3 \%)$ \\
\hline Malignant thymoma & $3(2.6 \%)$ \\
\hline Leukemia & $3(2.6 \%)$ \\
\hline Malignant lymphoma & $2(1.7 \%)$ \\
\hline Breast cancer & 1 \\
\hline Malignant mesothelioma & 1 \\
\hline Lung cancer & 1 \\
\hline Esophageal cancer & 1 \\
\hline Total & 116 \\
\hline
\end{tabular}

Modified from references [9] 
Table 13 Frequency of metastasis to the heart and the pericardium in autopsy cases

\begin{tabular}{|c|c|c|c|c|c|c|c|c|}
\hline Tumors & Autopsy & $\begin{array}{l}\text { AFIP } \\
\text { heart }\end{array}$ & Pericardium & Total $(\%)$ & Autopsy & Heart & $\begin{array}{l}\text { Mukai } \\
\text { Pericardium }\end{array}$ & Total $(\%)$ \\
\hline Malignant melanoma & 69 & 32 & 2 & $34(49)$ & 28 & 19 & 0 & $19(67.5)$ \\
\hline Germ cell tumor & 21 & 8 & 1 & $9(43)$ & 21 & 8 & 1 & $9(42.9)$ \\
\hline Leukemia & 202 & 66 & 2 & $68(34)$ & 103 & 20 & 2 & $22(21.4)$ \\
\hline Lung cancer & 1,037 & 180 & 112 & $292(28)$ & 484 & 04 & 32 & $136(28.1)$ \\
\hline Sarcoma & 159 & 24 & 11 & $35(22)$ & 90 & 14 & 3 & $17(18.9)$ \\
\hline Malignant lymphoma & 392 & 67 & 15 & $82(21)$ & 147 & 25 & 2 & $27(18.4)$ \\
\hline Breast cancer & 685 & 70 & 69 & $139(20)$ & 193 & 27 & 8 & $35(18.1)$ \\
\hline Esophageal cancer & 294 & 37 & 13 & $50(17)$ & 187 & 18 & 7 & $25(13.4)$ \\
\hline Renal cancer & 114 & 12 & 5 & $17(15)$ & 61 & 4 & 1 & $5(8.2)$ \\
\hline Oral cavity/tongue cancer & 235 & 22 & 2 & $24(10)$ & 104 & 16 & 3 & $19(18.3)$ \\
\hline Laryngeal cancer & 100 & 9 & 2 & $11(11)$ & 67 & 1 & 2 & $3(4.5)$ \\
\hline Thyroid cancer & 97 & 9 & 3 & $12(12)$ & 77 & 6 & 0 & $6(7.8)$ \\
\hline Uterine cancer & 451 & 36 & 5 & $41(9)$ & 195 & 18 & 2 & $20(10.3)$ \\
\hline Gastric cancer & 603 & 28 & 16 & $44(7)$ & 391 & 22 & 8 & $30(7.7)$ \\
\hline Colon cancer & 440 & 22 & 3 & $25(6)$ & 167 & 9 & 3 & $12(7.2)$ \\
\hline Pharyngeal cancer & 67 & 1 & 2 & $3(4.5)$ & 34 & 1 & 2 & $3(8.8)$ \\
\hline Urinary bladder cancer & 128 & 8 & 0 & $8(6)$ & 47 & 2 & 0 & $2(4.3)$ \\
\hline Ovarian cancer & 188 & 2 & 6 & $8(4)$ & 49 & 1 & 0 & $1(2.0)$ \\
\hline Prostate cancer & 171 & 6 & 0 & $6(4)$ & 48 & 1 & 0 & $1(2.0)$ \\
\hline Nasal/paranasal sinus cancer & 32 & 1 & 0 & $1(3)$ & 32 & 1 & 0 & $1(3.1)$ \\
\hline Pancreatic cancer & 185 & 6 & 0 & $6(3)$ & 89 & 2 & 0 & $2(2.2)$ \\
\hline Hepato-biliary cancer & 325 & 7 & 0 & $7(2)$ & 250 & 3 & 2 & $5(2.0)$ \\
\hline Malignant thymoma & & & & & 5 & 3 & 0 & $3(60.0)$ \\
\hline Skin cancer & & & & & 14 & 2 & 0 & $2(14.3)$ \\
\hline External genital cancer & & & & & 7 & 0 & 1 & $1(14.3)$ \\
\hline Neuroblastoma & & & & & 11 & 0 & 1 & $1(9.1)$ \\
\hline Unknown & & & & & 9 & 2 & 0 & $2(22.2)$ \\
\hline Others & & & & & 82 & 0 & 0 & 0 \\
\hline Total & 6,240 & 654 & 299 & $953(15)$ & 2,992 & 324 & 83 & 407 (13.6) \\
\hline
\end{tabular}

Modified from reference [9]

AFIP Armed Forces Institute of Pathology

angiosarcoma, 17 cases $(1.8 \%)$ of rhabdomyosarcoma, 5 cases $(1.0 \%)$ of malignant fibrous histiocytoma, and 2 cases $(0.4 \%)$ of osteosarcoma. As of pericardial tumor, two cases of malignant mesothelioma were reported. Tumors of the great vessels were extremely rare. Pulmonary artery tumors were most frequent, among them intimal sarcoma in five cases, angiosarcoma in two cases, and one case of leiomyosarcoma. Two cases of metastatic aortic tumors (thymic carcinoma, esophageal carcinoma) were reported, and in the vena cava tumors, one case of primary angiosarcoma and three metastatic tumors were reported.

Metastatic cardiac tumors

Pathway of metastasis from other organs to the heart or pericardium are direct invasion from nearby organs such as lung, mediastinum or esophagus, distant metastasis by lymphatic metastasis or hematogenous metastasis, extension of the tumor via vena cava or pulmonary vein to the heart chamber, or combination of these routes.

The incidence of metastatic cardiac tumors in autopsy cases has been reported $0.7-3.5 \%$ and in autopsy cases of malignant tumor has been reported 1.7-14\%; thus metastatic cardiac tumors are more frequent than malignant tumors originated from the heart [20] (Table 10). Lymburner [14] reported high incidence of metastatic cardiac tumors as 52 cases $(0.61 \%)$ and malignant tumors originated from the heart as 4 cases $(0.047 \%)$ in 8,550 autopsy cases, which ratio is $13: 1$ in 1934 .

Mukai et al. [15] reported that during a 10-year period (1976-1985), only one case of a primary malignant mesothelioma $(0.038 \%)$ was identified among 2,649 autopsies 
of malignant tumors at the National Cancer Center Hospital, in contrast, there were 407 cases $(15.4 \%)$ in which heart and/or pericardium were secondarily involved with a malignant tumor from other organs. Burke indicated that if one accepts a rate of 1 to $3 \%$ for cardiac metastases occur in autopsy, and a rate of 1 to $3 \%$ for malignant tumors originated from the heart seen in autopsy, then the ratio of cardiac metastases to malignant tumors originated from the heart is 100:1 to 1,000:1. They suggested that this estimate is so higher than previous estimate 1:20 to 1:40; thus, a ratio that falls within the range of 100 to $1,000: 1$ is likely an accurate estimate of the true ratio of metastatic tumors to malignant tumors originated from the heart [3]. Since Butany et al. [21] reported that two malignant tumors originated from the heart $(0.017 \%)$ and 264 metastatic tumors $(2.31 \%)$ were identified among 11,432 autopsies (the ratio of malignant tumors originated from the heart to metastatic tumors 1:132), Burke's estimate is plausible.

Lung cancer is the most high incident metastatic cardiac tumor followed by breast cancer, malignant melanoma, leukemia, and malignant lymphoma [15, 21] (Table 11). In our study about cardiac tumors in Japan supported by the Grant-in-aid for scientific research revealed that among 116 metastatic tumors, direct invasion to the heart was 32 cases $(27.6 \%)$, distant metastasis from other organ cancer was 39 cases $(34.5 \%)$, and intravenous extension of the tumor was 33 cases $(28.4 \%)$ (Table 12). As the rate of metastases to the heart and pericardium (number of cases with metastases to the heart/number of autopsy of malignancy for each $\times 100$ ), malignant melanoma most frequently metastasizes to the heart (49-67.5\%), followed by germ cell tumors (43\%), leukemia (21.4-34\%), malignant lymphoma (18.4-21\%), and others [3, 15] (Table 13).

Table 14 Metastatic sites of the heart and the pericardium

\begin{tabular}{lll}
\hline Sites & Mukai & Butany \\
\hline Heart/pericardium & 407 & \\
$\quad$ Heart: with or without pericardial & 329 & \\
$\quad$ involvement & & \\
$\quad$ Pericardium only & 78 & \\
Extent of involvement & & \\
$\quad$ Pericardium & $78(19.2 \%)$ & $127(65.8 \%)$ \\
Epicardium & $136(33.4 \%)$ & $48(24.9 \%)$ \\
Myocardium & $169(41.5 \%)$ & $56(29.0 \%)$ \\
Endocardium & $4(5.9 \%)$ & $6(3.1 \%)$ \\
Localization of involvement & & \\
Right side only & 34 & \\
Left side only & 50 & \\
Septum only & 10 & \\
Bilateral or diffuse & 52 & \\
Intracavitary tumor thrombus & 7 & \\
\hline
\end{tabular}

Modified from reference [9]
Bussani et al. [22] reported the study for an autopsy of 18,751 cases, and among 7,289 cases of malignant tumor metastasis to the heart was found in 622 cases $(9.1 \%)$. Malignant pleural mesothelioma showed the highest rate $(48.4 \%)$ of metastasis, followed by malignant melanoma $(27.8 \%)$ and lung adenocarcinoma (21\%). In addition, the frequency rate of lung cancer was different in accordance with the pathology of the lung cancer, and in adenocarcinoma it was $21 \%$, undifferentiated carcinoma $19.5 \%$, squamous cell carcinoma $18.2 \%$, and bronchoalveolar carcinoma $9.8 \%$.

The metastatic site of the metastatic tumor in the heart are to the heart, pericardium, and both heart and pericardium. Mukai et al. [15] reported that among 407 cases of cardiac metastasis, metastasis to the myocardium was 169 cases $(41.5 \%)$, followed by epicardium 136 cases (33.4\%), pericardium 78 cases (19.2\%), and endocardium 24 cases (5.9\%), and Butany et al. [21] reported that among 193 cases of cardiac metastasis, metastasis to the pericardium was 127 cases $(65.8 \%)$, myocardium 56 cases (29.0\%), epicardium 48 cases (24.9\%), and endocardium 6 cases $(3.1 \%)[12,21]$ (Table 14). The differences of the incidence of metastatic cardiac tumor by reporters may be due to what kind of hospital, i.e., general hospital, cancer specialized hospital or cardiovascular specialized hospital, or whether hospital has system to perform an autopsy and department pathology or not [21]. It is also possible that the statistical results are different depending on whether to include the hematopoietic tumors such as leukemia and malignant lymphoma. While there is a report that incidence of metastatic cardiac tumor does not significantly change with time [23], Mukai et al. [15] reported increase in its incidence from $9.7 \%$ in 1996 report to $15.4 \%$ in 1988. In addition, according to the study of the reported cases summarized by Al-Mamgani et al. [20], its incidence prior to 1975 was $3.8 \%$ and subsequent significant increased to $7.1 \%$ in recent years.

Formerly, most of the metastatic cardiac tumors have been so far reported in autopsy cases. Recent advances of diagnostic imaging methods by CT, MRI, and echocardiography enabled to discover metastasis to the heart early even in the absence of symptoms related to the heart, such as arrhythmia and heart failure [24]. In addition to these development of diagnostic tools, incidence of metastatic cardiac tumors may increase further by life-prolonging effect by anti-cancer drugs .

Acknowledgments This work was partially supported by the Japan Society for the promotion of science, Grant-in-aid for scientific research (C) 21591793. We wish to acknowledge the assistance of Dr. Yuko Wada and Mrs. Michie Futatsugi for data collection and analyses.

\section{Conflict of interest None.}


Open Access This article is distributed under the terms of the Creative Commons Attribution License which permits any use, distribution, and reproduction in any medium, provided the original author(s) and the source are credited.

\section{References}

1. Blondeau P. Primary cardiac tumors-French studies of 533 cases. Thorac Cardiovasc Surg. 1990;38:192-5.

2. Miller DV, Tazelaar HD. Cardiovascular pseudoneoplasm. Arch Pathol Lab Med. 2010;134:362-8.

3. Burke A, Virmani R. Tumors of the heart and great vessels. Atlas of tumor pathology, vol. 16. Washington DC: Armed Forces Institute of Pathology; 1996. p. 1-11. 3rd Series.

4. Burke AP, Veinot JP, Loire R, Virmani R, Tazelaar H, Kamiya H, Araoz PA, Watanabe G. Tumors of the heart. In: Travis WD, Brambilla E, Müller-Hermelink HK, Harris CC, editors. Tumours of the lung, pleura, thymus and heart. Lyon: JARC Press; 2004. p. $251-88$.

5. Orlandi A, Ferlosio A, Roselli M, Chiariello L, Spagnoli LG. Cardiac sarcoma. An update. J Thorac Oncol. 2010;5:1483-9.

6. Amano J, Yoshimura Y, Nakayama J. Classification of cardiac tumors. In: Amano J, Nakayama J, Ikeda U, editors. Textbook of cardiac tumors. Tokyo: Nanzando; 2011. p. 2-7.

7. Burke AP, Virmani R. Sarcomas of the great vessels. A clinicopathologic study. Cancer. 1993;71:1761-73.

8. Iwabuchi K. Aortic disease-aortic tumors. In: Syndrome Circulation, editor. IX. 2nd ed. Tokyo: Nippon Rinsho-Sha; 2008. p. 356-9.

9. Amano J, Nakayama J. Epidemiology and frequency of cardiac tumors. In: Amano J, Nakayama J, Ikeda U, editors. Textbook of cardiac tumors. Tokyo: Nanzando; 2011. p. 8-18.

10. Wold LE. Lie JT Cardiac myxomas: a clinicopathologic profile. Am J Pathol. 1980;101:219-40.

11. Pollia JA, Gogol LJ. Some notes on malignancies of the heart. Am J Cancer. 1936;21:363-6.

12. Straus R, Merliss R. Primary tumor of the heart. Arch Pathol. 1945;39:74-8.

13. Reynen K. Frequency of primary tumors of the heart. Am J Cardiol. 1996;77:107.

14. Lymburner RM. Tumours of the heart: histopathological and clinical study. Can Med Assoc J. 1934;30:368-73.

15. Mukai K, Shinkai T, Tominaga K, Shimosato Y. The incidence of secondary tumors of the heart and pericardium. A 10-year study. Jpn J Clin Oncol. 1988;18:195-201.
16. Nadas AS, Ellison RC. Cardiac tumors in infancy. Am J Cardiol. 1968;21:363-6.

17. McAllister HA Jr, Fenoglio JJ Jr. Tumors of the cardiovascular system. Atlas of tumor pathology. Washington DC: Armed Forces Institute of Pathology; 1978. p. 1-3. 2nd Series, Fascicle 15.

18. Becker AE. Primary heart tumors in the pediatric age group: a review of salient pathologic features relevant for clinicians. Pediatr Cardiol. 2000;21:317-23.

19. Endo A, Ohtahara A, Kinugawa T, Nawada T, Fujimoto Y, Mashiba $\mathrm{H}$, Shigemasa C. Clinical incidence of primary cardiac tumors. J Cardiol. 1996;28:227-34.

20. Al-Mamgani A, Baartman L, Baaijens M, de Pree I, Incrocci L, Levendag PC. Cardiac metastases. Int J Clin Oncol. 2008;13:369-72.

21. Butany J, Leong SW, Carmichael K, Komeda M. A 30-year analysis of cardiac neoplasms at autopsy. Can $\mathrm{J}$ Cardiol. 2005;21:675-80.

22. Bussani R, De-Giorgio F, Abbate A, Silvestri F. Cardiac metastases. J Clin Pathol. 2007;60:27-34.

23. Abraham DP, Reddy V, Gattusa P. Neoplasms metastatic to the heart: review of 3,314 consecutive autopsies. Am J Cardiovasc Pathol. 1990;3:195-8.

24. Chiles C, Woodard PK, Gutierrez FR, Link KM. Metastatic involvement of the heart and pericardium: CT and MR imaging. Radiographics. 2001;21:439-49.

\section{Author Biography}

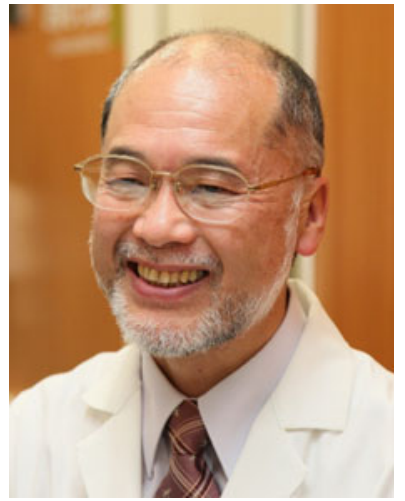

Jun Amano received his M.D. degree from Shinshu University in 1975 and $\mathrm{Ph} . \mathrm{D}$. degree from Juntendo University in 1980, respectively. He was a research fellow of the Department of Surgery, Harvard Medical School from 1983 to 1985 . He became a professor of surgery in Shinshu University Faculty of Medicine in 1997, and a councilor of Shinshu University from 2011. He specialized in cardiovascular surgery, and interested in translational research. 